\title{
Facts, Traditions, and Complications of Skin Whitening Products among Female Students in Sudan: A Cross-Sectional Study
}

\author{
Asma A. Abdalla ${ }^{1} \&$ Mafaz S. Ahmed ${ }^{2}$ \\ ${ }^{1}$ Associate Professor, Faculty of Medicine, University of Khartoum, Sudan \\ ${ }^{2} 6^{\text {th }}$ year Medical Student, Ibn Sina University, Faculty of Medicine, Sudan \\ Correspondence: Asma A. Abdalla, Associate Professor, Faculty of Medicine, University of Khartoum, Sudan. \\ E-mail: asmaabdella@hotmail.com
}

Received: December 8, 2019 Accepted: February 8, 2020 Online Published: February 21, 2020

doi:10.5539/gjhs.v12n3p103 URL: https://doi.org/10.5539/gjhs.v12n3p103

\begin{abstract}
The increased use of skin whitening products serves as a significant challenge for the health care unit. The progressive use of the whitening products exposes individuals to various risk factors and skin-related complications. This study aims to determine the usage of skin-whitening products among female students at Ibn Sina University, Sudan. It further intends to assess the complications and risk factors that may emerge due to the increased use of skin whitening products. It used a descriptive cross-sectional design following a questionnaire-based survey approach. The data was collected from 138 females (age 17 to 25 years), which was statistically analyzed. The results revealed that $47.4 \%$ of the population used skin-whitening products, where $58.8 \%$ were aged 20-22 years. It revealed a significant association of marital status ( $p$-value, 0.010$)$ and belief ( $p$-value, 0.001 ) with the use of skin whitening products. It concludes that increased usage of skin-whitening products leads to the occurrence of various complications. It stresses introducing educational and preventive programs to mitigate the use of harmful products.
\end{abstract}

Keywords: belief, cross-sectional study, marital status, skin whitening products, Sudan

\section{Introduction}

It is well recognized that the practice of skin-whitening is globally embedded in various ethnic groups (Naidoo, Khoza, \& Dlova, 2016). The preference towards the white color and the idea of its superiority among other skin colors have promoted the use of skin whitening products (Couteau \& Coiffard, 2016). The increased use of the skin-whitening products is evident from Zion Market Research (Zion Market Research, 2019), which highlighted sale of 2017, where it reached a figure of USD 4,075 million with 6.5\% increase in 2018, which is further expected to increase to 8.9 billion by 2027 (Statista, 2019). Various studies have assessed the use of skin-whitening products, referring it in different names such as "skin bleaching products," "skin whitening products," and "depigmenting agents," in Africa, North America, Europe, and Asia noting its prevalence to range from 27\% to 77\% (Shroff, Diedrichs, \& Craddock, 2018; Ribeiro, Estanqueiro, Oliveira, \& Sousa Lobo, 2015).

Hollinger, Angra, \& Halder (2018) noted the benefit of using the skin-whitening products. It highlighted that some whitening substance prove to be beneficial (antioxidants, protection of macromolecules, anti-proliferative activity, such as collagen against Ultra Violet (UV radiation and more) (Ribeiro et al., 2015; Gbetoh \& Amyot, 2016); whereas, a study has raised concerns due to reduction of melanin in the skin (Gillbro \& Olsson, 2016). Its increased complication has led to its ban in some countries (Hollinger, Angra, \& Halder, 2018). These skin products are inclusive of ingredients such as corticosteroids, hydroquinone, or mercury, which are effective in the lightening of the skin color Gbetoh \& Amyot, 2016; Gillbro \& Olsson, 2016). However, this ingredient also gives rise to the various health risks such as impaired wound healing, dermatitis, and adrenal suppression (Peltzer, \& Pengpid, 2017).

The increase in the skin whitening products is also accounted for its projection as a success promoting factor (Shankar \& Subish, 2016). These promotions have led to the escalated use of skin whitening products. An earlier study by Jose \& Ray (2018) has established that the complications of the skins promote due to lack of knowledge of the adverse effects caused by these whitening products. Such as Alghamdi's (2010) research on the Saudi population revealed that about $45.4 \%$ of the female population were unaware of the detrimental effect that can 
emerge as a result of continual and aggressive use of the skin whitening products.

Previous studies on the developing countries and its prevailing culture have revealed the symbolizing of the light-colored skin as a form of social advantage for marital and career prospects (Shroff, Diedrichs, \& Craddock, 2018). This is notably relevant for countries such as Japan, Sudan, Malaysia, China, Thailand and more where fair skin color is reflected as a cultural marketer for class, wealth and social status (Jang et al., 2013). This stereotypical culture and notion related to beauty are reinforced by the produced advertisements (2017). This advertisement of the skin whitening products is regarded as akin to "disease mongering," which increases the people's insecurities (Shankar, Giri, \& Palaian, 2006). Burger et al. (2016) study asserted that the use of the whitening products could increase the medical need of an individual who may be suffered from some type of dermatological conditions that may be associated with the abnormal melanin (such as melasma, senile lentigo, etc.).

Assessment of the previous literature work has revealed that several societies across the world appreciate light skin as a form of beauty standard, whereas some regard it as a form of social capital (January et al., 2018). Agorku et al. (2016) research on Ghanaian women showed that use of the skin whitening product led to an increase in skin-related disease. In the same context, Kouotou et al. (2017) study on four university campuses of Yaoundé demonstrated that use of skin whitening products progresses due to the desire to have a uniform body skin color, following the desire for soft skin. Similarly, some studies on the five Association of Southeast Asian Nations (ASEAN) university students showed a high prevalence of skin whitening products due to the beauty standards, social practices, and cultural norms (Peltzer \& Pengpid, 2017; Rusmadi et al., 2015). Earlier study of Ahmed \& Hamid's (2017) on the University of Sudan stated that females had tried skin whitening products.

Despite the study on the Sudanese undergraduate population and increased use of skin lightening products (SLP) in Sudan (Ahmed \& Hamid, 2017; Yousif et al., 2014), the understandings of the motivating factors for the use of the skin whitening products remain inadequate. Accordingly, the other relevant factors, such as age and social status, are also found to be neglected among the previous researches, along with the complications that follow it. Such as Ahmed \& Hamid (2016) have stressed that since university population is an elite group in the region, therefore, addressing the use of the skin-whitening products among this group is said to address the prevalence among the general public. Therefore, the present study intends to assess the proportion of skin whitening among females in Ibn Sina University, Sudan. It also examines the factors that lead to increased use of the skin whitening product. The rationale behind the selection of the university population is based on the established claim that these are more vulnerable to the social practices and susceptible to social impact such as conformity (Kouotou et al., 2017).

\section{Methodology}

\subsection{Study Design}

The study used a descriptive cross-sectional study design to assess the factors that promote the use of skin whitening products among the female students in Sudan.

\subsection{Study Variables}

Age and marital status were considered as dependent variables; whereas, the use of the skin whitening product was considered an independent variable.

\subsection{Study population}

The inclusion criteria were prepared to target participants who were female, enrolled in Sudanese Universities, and the 2017-2018 class. The population of the study includes female medicinal students enrolled in the Ibn Sina University, Sudan. 138 students were systematically recruited in the study from 2nd, 3rd, 4th, 5th, and 6th years in the study year of 2017-2018. The inclusion criteria also required them to be aged between 17-26 years. These participants were selected as these were the primary target audience of the whitening cosmetic brands, which help gather results that can be generalized. This also falls in-line with the research findings of Ahmed \& Hamid (2016), who concluded this group findings as the one that can address the problem generally faced among the masses. The sample size of the study was computed using the sample size formula:

$$
N={\frac{P Q(Z)}{D^{2}}}^{2} \mathrm{~N}=138
$$

Where,

$\mathrm{N}=$ Sample Size $=138$

$\mathrm{Z}=$ Confidence Interval (1.96) 
$\mathrm{P}=$ Expected Proportion $(90 \%=0.9)$

$\mathrm{D}=$ Precision $(0.05)$

$\mathrm{Q}=$ Remaining Proportion $(1-\mathrm{p}=0.1)$

The compliance with the determined inclusion and exclusion criteria limited the number of participants to 136 only. Cohen, Monion, and Morris (2000) stated that a sample of 100 participants in survey research was adequate for representing a sub-group in a population. Singh and Masuku (2014) also found this sample size adequate for concluding results that can be generalized. Also, since the study uses a descriptive cross-sectional study design, this sample is found adequate.

\subsection{Data Collection}

Data selection was of selective random proportions. Data collection was part of a complementary research project in medicine community from 2017 to 2018. In the present study, data was collected through a survey using a self-administered close-ended questionnaire. The items of the questionnaire were distributed into two parts, where, first part gathered demographic details of the participants while the other collected information on the use of the skin whitening products.

\subsection{Data Analysis}

For determining the use of skin whitening products and their associated factors, descriptive cross-sectional design was adopted. The collected data were computed using IBM SPSS (Statistical Package for the Social Sciences) Version 23.0. The data were analyzed in the form of percentages. Along with it, chi-square was also used for determining the p-value. The study employed a quantitative approach for assessing the impact based on the fact that it allows the statistical processing of the data.

\subsection{Ethical Clearance}

Ethical approval from the ethical committee of Ibn Sina University Medical faculty was obtained. Written consent was taken from each participant. Participants were also communicated their right to withdraw from the study at any time.

\section{Results}

The responses of the participants revealed that the majority of the participants had not used skin-whitening products $(52.6 \%)$, while only few participants frequently use it $(21.1 \%)$. Occasional use of the skin whitening products was reported by (26.3\%) of the students (Figure 1).

\section{Do you use or have ever used any skin whitening products?}

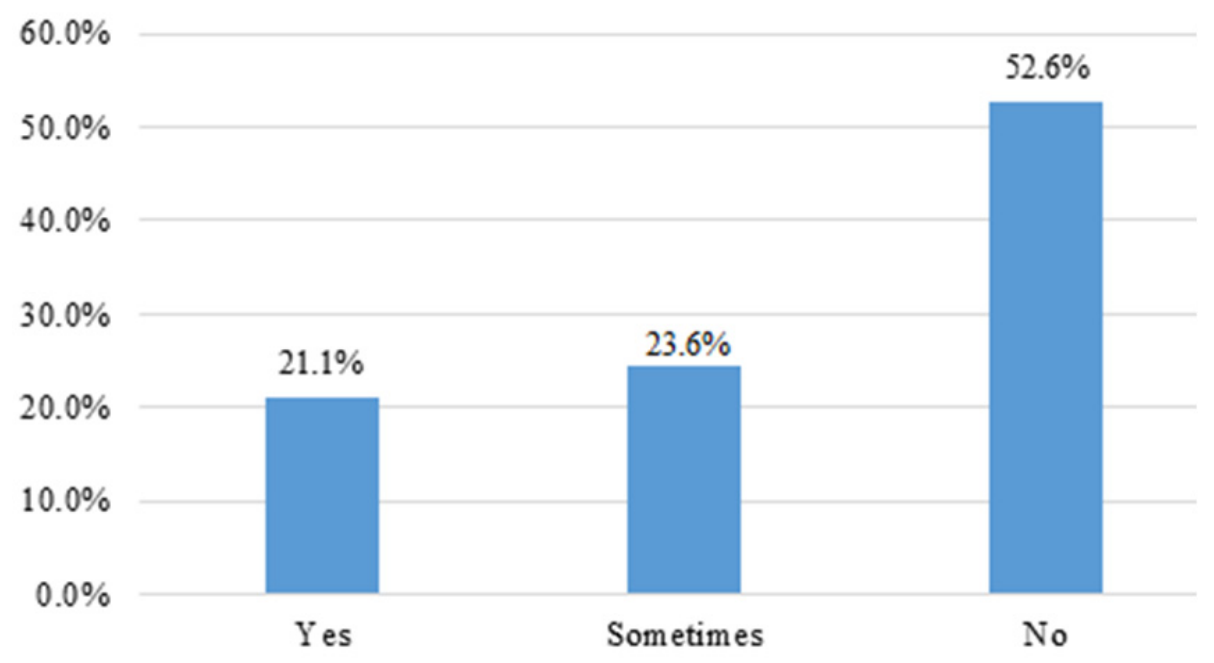

Figure 1. Usage of Skin Whitening Products among Ibn Sina Medical Female Students, 2017-2018

The response revealed that $86 \%$ had experienced different forms of skin complications. Among the different complications, majority responded the skin redness $(\mid 33.3 \%)$ and acne $(27.0 \%)$ were the major skin problems 
(Figure 2).

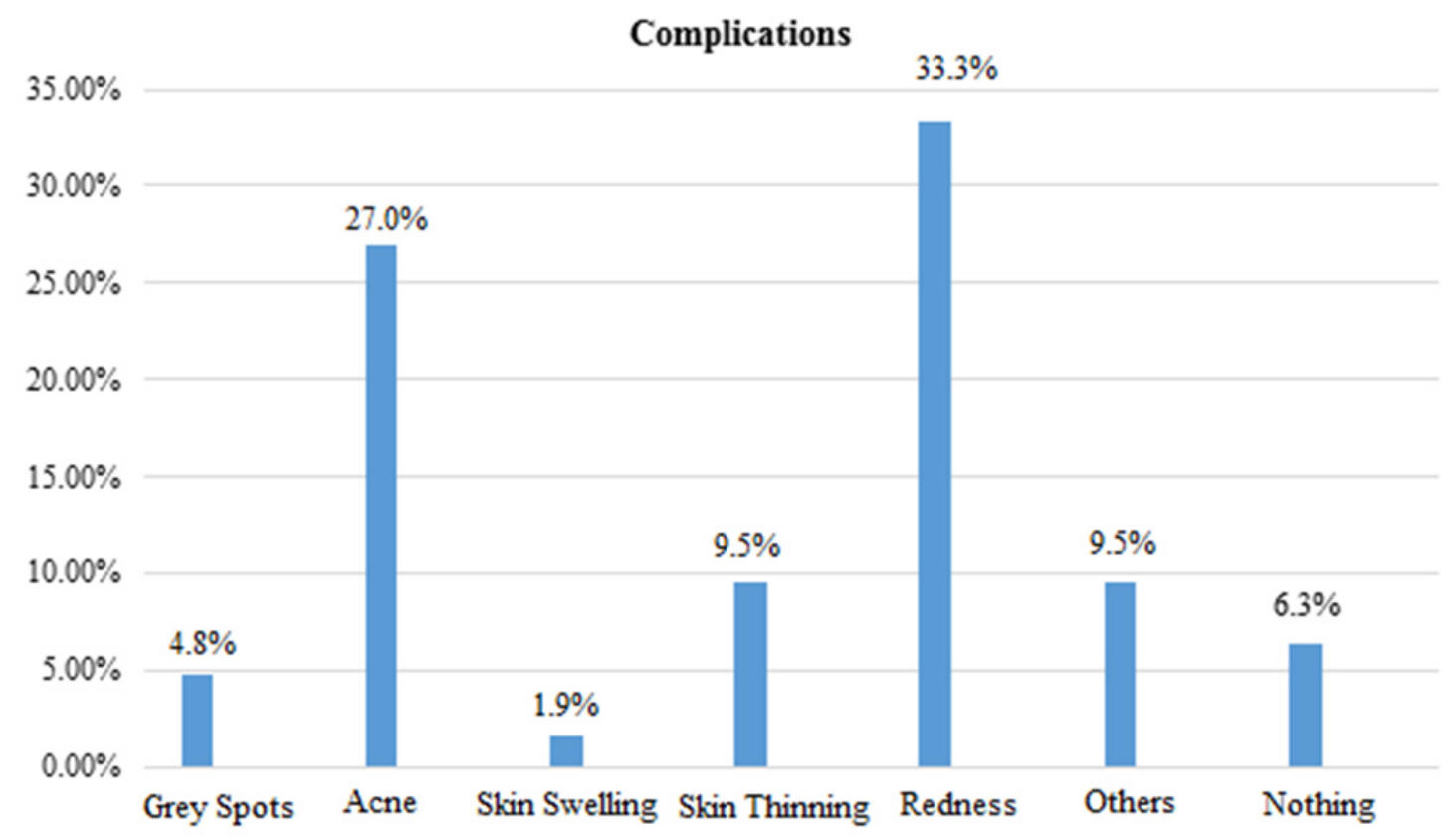

Figure 2. Complications due to SLP usage among Ibn Sina University student 2017-2018

Table 1 shows the responses of the participants concerning the use of skin-whitening products. The findings show that major use of the skin whitening products was from participants that were aged 20-22 (58.8\%), following the age group below 22 years $(26.0 \%)$. The achieved p-value also indicates an insignificant association of age with the use of skin-whitening products $(0.330)$. Concerning the marital status, the responses indicate that single participants $(89.5 \%)$ were involved with its usage following the married participants $(6.8 \%)$. The computed p-value highlights the strong impact of marital status on skin-products usage $(0.010)$. The collected responses of the participants revealed that $35.3 \%$ of them do not consider fairer skin as a necessity for obtaining a life partner; whereas, $30.1 \%$ considered it essential. The remaining $34.6 \%$ responded neutrally to it. However, the obtained p-value (0.001) illustrates that there is a strong association between the use of the skin whitening product and the belief that fairer skin tone is essential for obtaining a life partner.

Table 1. White Skin Association with Age, Marital Status and Life-Partner

\begin{tabular}{llll}
\hline Variables & & Percentage & P-value \\
\hline Age & & & 0.330 \\
& $<20$ years & $15.3 \%$ & \\
& $20-22$ years & $58.8 \%$ & \\
& $>22$ years & $26.0 \%$ & \\
\hline Marital Status & & & 0.010 \\
& Single & $89.5 \%$ & \\
& Married & $6.8 \%$ & \\
\hline Fair Skin is essential for obtaining life-partner & Others & $3.8 \%$ & \\
& & & \\
& Yes & $30.001 \%$ & \\
& No & $35.3 \%$ & \\
& Sometimes & $34.6 \%$ & \\
\hline
\end{tabular}




\section{Discussion}

Skin whitening is observed as a significant global health concern in developing countries. The prevalence of skin whitening products is substantially progressing, which raises severe concerns related to skin complication. The current findings reveal that various factors promote the use of skin whitening products in the Sudanese population. These outcomes are corroborated by the findings of Hamid et al. (2013), which assessed the use of products among the students of the University of Gezira in Sudan. Its comparative analysis showed that the use of products has mitigated in the country, which may account for the difference in the beauty scale between towns and cities. However, Lartey et al.'s (2017) study contradicts the current study findings showing that about 76 percent of the population in Ghana (Accra region) uses more than one whitening product.

Previous studies established the prevalence of usage among the students. Such as Alghamdi [13] noted that frequent use of the products leads to an increase in the complication of the skin based on its inclusion of the lightening agents, which reduces the skins' melanin concentration. The present study also revealed that age is one of the prime contributors which promotes the usage of skin whitening products among the Sudanese population. These findings align with the study outcomes of Hamed et al. (2010), which showed high involvement of the age group from 20 to 30 years in using the skin whitening products. These are also supplemented by the study of Askari et al. (2013), which noted that about 72 percent of the population within this specific group is inclined towards its use. Ravichandran (2013) also endorses the findings stating that major lightening cream complications were observed among individuals who reside in 20 to 30 years age group.

The present study showed that single students were more inclined towards the use of whitening products. These findings are similar to the earlier findings where the majority of the individuals in the developing countries were using whitening products. Such as Shroff, Diedrichs, \& Craddock's (2018) findings on the Indian population produced similar results indicating that individuals, with single marital status, are the frequent purchaser of the skin whitening products. Likewise, as the current study findings, it also showed that cultural norms and belief of finding a partner is linked with the color of the skin. Landor \& Halpern (2016) also corroborate the present study results stating that skin color acts as a determiner of marriage, which eventually promotes the use of skin whitening products. Hamilton, Goldsmith, \& Darity (2009) also endorse the idea and stated it as a promoter of the usage among individuals, particularly females. Similarly, Dlova et al. (2015) also showed the impact of marital status on the consumption of skin whitening products. Ahmed and Hamid (2017) also reported that lack of confidence also accounts for increased use of these products.

Moreover, this study acknowledges the limitation highlighting that the restriction to a specific region confines the generalizability of the results. It is because the different socio and economic conditions affect the usage of the skin-whitening products. Similarly, the small sample size and application of the quantitative approach further sets parameters on its finding. Therefore, in order to overcome these, this study recommends the evaluation of large population sample implications, which highlight the consequence of skin whitening in the long-run and assesses the motivation factors for the use of SLP. Such as students from more than one university can be included along with no age restriction as set in the present study. Also, a qualitative method can be adopted where interviews can be conducted with industry professionals, consumers, or the manufacturer to provide different perspectives on the current subject. This also helps overcome the current limitations and expand the current horizon of the study. Also, it also suggests examining the effective alternative procedures that are not harmful and which individuals may adopt. Accordingly, examining the use of skin-whitening products among pregnant women is also observed to contribute to the knowledge horizon as well as its health implication upon the infant.

\section{Conclusion}

The findings of this cross-sectional study showed the low prevalence and use of whitening products among the students of Ibn Sina University. These results established that the use of skin whitening products is promoted due to various factors such as age, marital status, and beauty desire. It noted that the use of such products is more among the single status females for their desire to attain a life partner. The results shed light on the use of whitening products among the Sudanese female population. It is noted that belief that fairness leads to the attainment of the partner is a firmly held among the participants. The study suggests that regional authorities should initiate awareness as well as educational programs for improving their population literacy-related to skin complications. The campaigns should be instigated, which promotes the idea to feel confident in ones' own skin. Also, continuous monitoring of the use of skin whitening products should be conducted. Moreover, knowledge about early complication signs and its immediate treatment for the prevention of skin cancer or ovarian should be promoted. 


\section{Consent}

Ethical approval was obtained from the medicine faculty of Ibn Sina University. Written informed consent from participant students was taken.

\section{Competing Interests Statement}

The authors declare that there are no competing or potential conflicts of interest.

\section{References}

Agorku, E. S., Kwaansa-Ansah, E. E., Voegborlo, R. B., Amegbletor, P., \& Opoku, F. (2016). Mercury and hydroquinone content of skin toning creams and cosmetic soaps, and the potential risks to the health of Ghanaian women. SpringerPlus, 5(1), 319. https://doi.org/10.1186/s40064-016-1967-1

Ahmed, A. E., \& Hamid, M. E. (2016). A Survey of Female Sudanese College Students' Knowledge and Attitude towards Skin Lightening. J Womens Health, Issues Care 5(4), 2. https://doi.org/10.4172/2325-9795.1000237

Ahmed, A. E., \& Hamid, M. E. (2017). Use of Skin-Whitening Products by Sudanese Undergraduate Females: a Survey. Journal of racial and ethnic health disparities, 4(2), 149-155. https://doi.org/10.1007/s40615-016-0212-5

Alghamdi, K. M. (2010). The use of topical bleaching agents among women: a cross-sectional study of knowledge, attitude, and practices. Journal of the European Academy of Dermatology and Venereology, 24(10), 1214-1219. https://doi.org/10.1111/j.1468-3083.2010.03629.x

Askari, H., Sajid, A., Faran, Z., \& Sarwar, S. Z. (2013, February). Skin-lightening practice among women living in Lahore: prevalence, determinants, and user's awareness. In 3rd International Conference on Business Management.

Burger, P., Landreau, A., Azoulay, S., Michel, T., \& Fernandez, X. (2016). Skin whitening cosmetics: Feedback and challenges in the development of natural skin lighteners. Cosmetics, 3(4), 36. https://doi.org/10.3390/cosmetics3040036

Cohen, L., Monion, L., \& Morris, K. (2000). Research methods in education (5th ed.). London UK and New York.

Couteau, C., \& Coiffard, L. (2016). Overview of skin whitening agents: Drugs and cosmetic products. Cosmetics, 3(3), 27. https://doi.org/10.3390/cosmetics3030027

Dlova, N. C., Hamed, S. H., Tsoka-Gwegweni, J., \& Grobler, A. (2015). Skin lightening practices: an epidemiological study of South African women of African and Indian ancestries. British Journal of Dermatology, 173, 2-9. https://doi.org/10.1111/bjd.13556

Gbetoh, M. H., \& Amyot, M. (2016). Mercury, hydroquinone and clobetasol propionate in skin lightening products in West Africa and Canada. Environmental research, 150, 403-410. https://doi.org/10.1016/j.envres.2016.06.030

Gillbro, J. M., \& Olsson, M. J. (2011). The melanogenesis and mechanisms of skin-lightening agents-existing and new approaches. International journal of cosmetic science, 33(3), 210-221. https://doi.org/10.1111/j.1468-2494.2010.00616.x

Hamed, S. H., Tayyem, R., Nimer, N., \& AlKhatib, H. S. (2010). Skin-lightening practice among women living in Jordan: prevalence, determinants, and user's awareness. International journal of dermatology, 49(4), 414-420. https://doi.org/10.1111/j.1365-4632.2010.04463.x

Hamid, H. A. E. (2013). Serum Zinc, Iron and Copper Profiles of Sudanese Patients with Visceral leishmaniasis (Kala-azar) in Gedarif State, Eastern Sudan (Doctoral dissertation, University of Gezira).

Hamilton, D., Goldsmith, A. H., \& Darity, W. (2009). Shedding "light" on marriage: The influence of skin shade on marriage for black females. Journal of Economic Behavior \& Organization, 72(1), 30-50. https://doi.org/10.1016/j.jebo.2009.05.024

Hollinger, J. C., Angra, K., \& Halder, R. M. (2018). Are natural ingredients effective in the management of hyperpigmentation? A systematic review. The Journal of clinical and aesthetic dermatology, 11(2), 28.

Jang, H., Koo, F. K., Ke, L., Clemson, L., Cant, R., Fraser, D. R., \& Brock, K. (2013). Culture and sun exposure in immigrant East Asian women living in Australia. Women \& health, 53(5), 504-518. https://doi.org/10.1080/03630242.2013.806386

January, J., Muchenje, R. R., Gonah, L., Shamu, S., \& Tapera, R. (2018). Use of skin lightening creams among 
female University students in Zimbabwe: a preliminary survey. Medical Journal of Zambia, 45(1), 44-48.

Jose, A., \& Ray, J. G. (2018). Toxic content of certain commercially available fairness creams in Indian market. Cogent Medicine, 5(1), 1433104. https://doi.org/10.1080/2331205X.2018.1433104

Kouotou, E. A., Nansseu, J. R. N., Adegbidi, H., Mebara, T. C. J. Z., \& Ndam, E. C. N. (2017). Skin whitening among Cameroonian female university students: knowledge, attitudes, practices, and motivations. BMC women's health, 17(1), 33. https://doi.org/10.1186/s12905-017-0385-z

Landor, A. M., \& Halpern, C. T. (2016). The enduring significance of skin tone: Linking skin tone, attitudes toward marriage and cohabitation, and sexual behavior. Journal of youth and adolescence, 45(5), 986-1002. https://doi.org/10.1007/s10964-016-0456-8

Lartey, M., Krampa, F. D., Abdul-Rahman, M., Quarcoo, N. L., Yamson, P., Hagan, P. G., \& Adjei, A. A. (2017). Use of skin-lightening products among selected urban communities in Accra, Ghana. International journal of dermatology, 56(1), 32-39. https://doi.org/10.1111/ijd.13449

Naidoo, L., Khoza, N., \& Dlova, N. (2016). A fairer face, a fairer tomorrow? A review of skin lighteners. Cosmetics, 3(3), 33. https://doi.org/10.3390/cosmetics3030033

Peltzer, K., \& Pengpid, S. (2017). Knowledge about, attitude toward, and practice of skin lightening products use, and its social correlates among university students in five Association of Southeast Asian Nations (ASEAN) countries. International journal of dermatology, 56(3), 277-283. https://doi.org/10.1111/ijd.13518

Ravichandran, N. (2013). Skin whitening creams can cause long-term damage, doctors warn. Mail Online India.

Ribeiro, A., Estanqueiro, M., Oliveira, M., \& Sousa Lobo, J. (2015). Main benefits and applicability of plant extracts in skin care products. Cosmetics, 2(2), 48-65. https://doi.org/10.3390/cosmetics2020048

Rusmadi, S. Z., Ismail, S., Norkhadijah, S., \& Praveena, S. M. (2015). Preliminary study on the skin lightening practice and health symptoms among female students in Malaysia. Journal of environmental and public health, 2015. https://doi.org/10.1155/2015/591790

Shankar, P. R., \& Subish, P. (2016). Fair skin in South Asia: an obsession?. Journal of Pakistan Association of Dermatology, 17(2), 100-104.

Shankar, P. R., Giri, B. R., \& Palaian, S. (2006). Fairness creams in South Asia-A case of disease mongering?. PLoS medicine, 3(7), e315. https://doi.org/10.1371/journal.pmed.0030315

Shroff, H., Diedrichs, P. C., \& Craddock, N. (2018). Skin color, cultural capital, and beauty products: an investigation of the use of skin fairness products in Mumbai, India. Frontiers in public health, 5, 365. https://doi.org/10.3389/fpubh.2017.00365

Singh, A. S., \& Masuku, M. B. (2014). Sampling techniques \& determination of sample size in applied statistics research: An overview. International Journal of Economics, Commerce and Management, 2(11), 1-22.

Statista. (2019). Forecasted market value skin lightening products worldwide from 2017 to 2027 (in million U.S. dollars). https://www.statista.com/statistics/863876/global-forecasted-market-value-of-skin-lightening-products/

Tuan Anh, T. (2017). Beauty Products Advertisements: A Discourse Analysis. Journal of Science, Social Science, 62(5), pp.127-133. https://doi.org/10.18173/2354-1067.2017-0043

Yousif, A. K., Ahmed, A. A., Idris, A. E., Elmustafa, M. O., \& Ahmed, E. H. (2014). The use of bleaching creams among Central Sudan Students, 2010. https://doi.org/10.4236/pp.2014.55063

Zion Market Research. (2019). Global Skin Lightening Products Market Will Reach USD 8,895 Million By 2024: Zion Market Research. Globe News Wire. Retrieved from https://www.globenewswire.com/news-release/2019/01/10/1685903/0/en/Global-Skin-Lightening-ProductsMarket-Will-Reach-USD-8-895-Million-By-2024-Zion-Market-Research.html

\section{Copyrights}

Copyright for this article is retained by the author(s), with first publication rights granted to the journal.

This is an open-access article distributed under the terms and conditions of the Creative Commons Attribution license (http://creativecommons.org/licenses/by/4.0/). 